\title{
Caracterização de rizóbios indicados para produção de inoculantes por meio de sequenciamento parcial do $16 S$ rRNA
}

\author{
Bethânia Figueiredo Barbosa de Toledo ${ }^{(1)}$, Jackson Marcondes(1) \\ e Eliana Gertrudes de Macedo Lemos ${ }^{(1)}$
}

(1)Universidade Estadual Paulista, Faculdade de Ciências Agrárias e Veterinárias, Departamento de Tecnologia, Rodovia Paulo Donato
Castellane, s/no, CEP 14884-900 Jaboticabal, SP. E-mail: bebarbosa@bol.com.br, jackson@fcav.unesp.br, egerle@fcav.unesp.br

Resumo - O objetivo deste trabalho foi confrontar as sequências parciais do gene 16S rRNA de estirpes padrão de rizóbios com as de estirpes recomendadas para a produção de inoculantes no Brasil, com vistas à verificação da confiabilidade do sequenciamento parcial desse gene para a identificação rápida de estirpes. Foram realizados sequenciamentos através de reação em cadeia da polimerase (PCR) com iniciadores relativos à região codificadora do gene $16 S$ rRNA entre as bactérias estudadas. Os resultados foram analisados pela consulta de similaridade de nucleotídeos aos do "Basic Local Alignment Search Tool” (Blastn) e por meio da interpretação de árvores filogenéticas geradas usando ferramentas de bioinformática. A classificação taxonômica das estirpes Semia recomendadas para inoculação de leguminosas com base em propriedades morfológicas e especificidade hospedeira não foi confirmada em todas as estirpes. A maioria das estirpes estudadas, consultadas no Blastn, é consistente com a classificação proposta pela construção de árvores filogenéticas das sequências destas estirpes, com base na similaridade pelo sequenciamento parcial do gene considerado.

Termos para indexação: Bradyrhizobium, Rhizobium, filogenia.

\section{Characterization of rhizobia indicated for inoculant production using $16 S$ rRNA partial sequencing}

\begin{abstract}
The aim of this work was to compare the partial sequences of 16S rRNA gene of rhizobia strain patterns already classified with strains recommended for the production of inoculants in Brazil, in order to verify the reliability of partial sequencing of the gene for the purpose of rapid identification of strains. Polymerase Chain Reaction (PCR) sequencing using primers on the coding region of the 16S rRNA gene among the bacteria studied was conducted. The results were analyzed by consulting the nucleotides' similarity based on Basic Local Alignment Search Tool (Blastn) and by interpreting the phylogenetic trees generated by bioinformatic tools. The taxonomic classification of Semia strains recommended for legume inoculation based on morphological properties and host specificity was not confirmed in all strains. The similarity of the Blastn consultation by partial sequencing of the gene found in strains studied is consistent with the classification proposed by the construction of a phylogenetic tree of sequences of strains in most cases.
\end{abstract}

Index terms: Bradyrhizobium, Rhizobium, phylogeny.

\section{Introdução}

A inoculação de bactérias diazotróficas simbióticas em algumas leguminosas de importância agronômica dispensa a aplicação de adubos nitrogenados nos solos, o que reduz o custo de produção, e provê equilíbrio ambiental. Contudo, a indicação de uma estirpe de rizóbio como inoculante comercial requer estudos que permitam avaliar seu potencial para estabelecer a associação, fixar simbioticamente o nitrogênio e competir com outras bactérias nativas no solo.
Existem coleções de estirpes isoladas e recomendadas, porém muitas ainda requerem uma classificação sistemática adicional que permita um agrupamento e uma diferenciação mais apropriada, além de novas identificações, que possibilite uma recomendação adequada do uso dessas estirpes bacterianas.

No Brasil, a recomendação de estirpes de rizóbios ficou a cargo da Rede de Laboratórios para Recomendação, Padronização e Difusão de Tecnologia de Inoculantes Microbianos de Interesse 
Agrícola (Relare). A Fundação Estadual de Pesquisa Agropecuária (Fepagro) tem a atribuição de manter uma coleção e preservar e distribuir as estirpes para as indústrias. Essa coleção é reconhecida internacionalmente, porém ainda faltam estudos e informações taxonômicas sobre as estirpes, com base em métodos moleculares aceitos atualmente. As estirpes da coleção da Fepagro são classificadas como Rhizobium meliloti, R. leguminosarum, Bradyrhizobium japonicum, Bradyrhizobium sp., $R$. fredii ou $R$. loti, com base no grupo de inoculação cruzada, no crescimento rápido ou lento e na reação ácida ou alcalina em meio de cultura que contém manitol como fonte de carbono (Fundação Estadual de Pesquisa Agropecuária, 1999).

Nas análises que consideram o gene 16S rRNA, os rizóbios (alfaproteobactérias da ordem Rhizobiales), classificados inicialmente apenas na família Rhizobiaceae, foram classificados nas famílias Rhizobiaceae (gêneros Rhizobium, Sinorhizobium e Ensifer), Phyllobacteriaceae (Mesorhizobium), Bradyrhizobiaceae (Bradyrhizobium) e Hyphomicrobiaceae (Azorhizobium) (Garrity \& Holt, 2001). São descritas 54 espécies até o momento, das quais 23 são representantes do gênero Rhizobium (inclusive as bactérias do antigo gênero Agrobacterium e Allorhizobium), 11 do gênero Ensifer, uma do gênero Sinorhizobium, 11 do gênero Mesorhizobium, seis do gênero Bradyrhizobium e duas do gênero Azorhizobium (Garrity et al., 2007).

A caracterização de estirpes da coleção, que considera genes conservados e simbióticos, é essencial para comparar e identificar os rizóbios nativos dos solos brasileiros e para entender as relações entre planta e simbionte. Essa classificação pode ser realizada com marcadores moleculares. O produto do gene $16 S$ rRNA é o principal componente da subunidade ribossômica menor dos procariotos (Brosius et al., 1978), constituída por moléculas de ácido ribonucleico e proteínas, a qual é parte do maquinário celular responsável pela síntese proteica. Assim, esse gene está presente em todas as bactérias, apresenta características conservativas ao longo da evolução e pode servir como indicador de como os microrganismos estiveram relacionados durante a evolução ao longo de milhões de anos (Olsen \& Woese, 1993). Ferramentas que possibilitem a identificação de estirpes de maneira rápida, segura e com baixo custo são de extrema importância.

O objetivo deste trabalho foi confrontar as sequências parciais do gene 16S rRNA de estirpes padrão de rizóbios com as de estirpes recomendadas para a produção de inoculantes no Brasil, com vistas à verificação da confiabilidade de sequenciamento parcial desse gene para a identificação rápida de estirpes.

\section{Material e Métodos}

Os organismos utilizados neste trabalho não oferecem risco para o meio ambiente e saúde humana, encaixando-se no padrão de biossegurança NB-1. As estirpes padrão utilizadas foram obtidas no Laboratorium voor Microbiologie da Universiteit Gent (Bélgica) e no Laboratorie de Microbiologie de Soils do Institut Scientifique de Recherche Agronomique (INRA, França). As estirpes Semia (Seção de Microbiologia Agrícola da Secretaria da Agricultura do Rio Grande do Sul) foram obtidas na Fepagro. Todas foram cultivadas e mantidas no Laboratório de Bioquímica de Microrganismose Plantas, Departamento de Tecnologia, Faculdade de Ciências Agrárias e Veterinárias, Universidade Estadual Paulista.

As estirpes foram cultivadas e mantidas em meio “yeast mannitol agar" (YMA) (Vincent, 1970), com vermelho-congo, em estufa $\mathrm{BOD}$, a $28^{\circ} \mathrm{C}$. Foram posteriormente transferidas repetidamente (três vezes) para meio "triptone-yeast medium" (TY) (Beringer, 1974) sólido, com a finalidade de diminuir a produção de exopolissacarídeos, e, então, cultivadas durante 48 horas a $28^{\circ} \mathrm{C}$ sob agitação de $180 \mathrm{rpm}$ em meio de cultivo TY líquido. A suspensão de bactérias foi centrifugada a $12.000 \mathrm{~g}$, por $30 \mathrm{~min}$, a $4^{\circ} \mathrm{C}$. O sedimento foi lavado com $\mathrm{NaCl}$ 0,85\%, para a remoção de polissacarídeos extracelulares e possíveis resíduos do meio de cultivo. A suspensão foi novamente centrifugada para a obtenção das células, que foram utilizadas para a extração do DNA.

A extração do DNA genômico das bactérias seguiu o procedimento descrito por Sambrook et al. (1989). Nos cálculos da concentração do DNA, considerou-se que uma unidade de absorbância a $260 \mathrm{~nm}$ equivale a $50 \mu \mathrm{g}$ de DNA por mililitro de solução (Sambrook et al., 1989) e, na confirmação da concentração, foi realizada comparação da intensidade das bandas de pGEM com concentrações conhecidas, por meio de eletroforese em gel de agarose a $0,8 \%$.

$\mathrm{Na}$ amplificação da sequência conservada do gene $16 S$ rRNA, foram utilizados iniciadores universais pA “forward” 5' - AGA GTT TGA TCC TGG CTC AG -3', localização em E. coli: bases 8 a 27, e pc5B "reverse" 5'- 
TAC CTT GTT ACG ACT T-3', localização em E. coli: bases 1507 a 1492 (Wilson et al., 1990), o que resultou em fragmentos de sequências de aproximadamente 1,5 kb. As reações de PCR (reação em cadeia da polimerase) utilizaram tampão $20 \mathrm{mM}$ Tris- $\mathrm{HCl}$, $\mathrm{pH} 8,4$, contendo $50 \mathrm{mM} \mathrm{KCl}, 200 \mu \mathrm{M}$ de cada deoxinucleotídeo, 1,5 mM de $\mathrm{MgCl}_{2}$, 50 pmols de cada iniciador, 2,5 U de Taq DNA polimerase (Invitrogen, Brasil) e 50 ng de DNA, água Milli-Q (Millipore) previamente filtrada para um volume final de $50 \mu \mathrm{L}$. As amostras foram colocadas em um termociclador modelo PTC-100 (MJ Research Inc., EUA), para amplificação do gene, com o programa: 2 min a $94^{\circ} \mathrm{C}$; 30 ciclos de $50^{\circ} \mathrm{C}$ por $30 \mathrm{~s}, 72^{\circ} \mathrm{C}$ por $60 \mathrm{~s}, 94^{\circ} \mathrm{C}$ por $30 \mathrm{~s} ; 5$ min a $72^{\circ} \mathrm{C}$.

Os produtos da PCR foram purificados usando a enzima ExoSAP-IT (USB) antes do sequenciamento. Para tal, foram adicionados $2 \mu \mathrm{L}$ da enzima a $5 \mu \mathrm{L}$ do produto de PCR, que foram mantidos a $37^{\circ} \mathrm{C}$ por 15 min para degradar o excesso de iniciadores e nucleotídeos da reação. As amostras foram posteriormente mantidas a $80^{\circ} \mathrm{C}$ por $15 \mathrm{~min}$, para a inativação da enzima ExoSAP-IT (USB). As amplificações por PCR para sequenciamento dos fragmentos do gene $16 S$ rRNA previamente obtidos foram realizadas em microplacas usando os iniciadores pA-F e pc5B-R de forma independente. Foram utilizados: $0,4 \mu \mathrm{L}$ de "DNA sequencing" (Big Dye Terminator Cycle Sequencing - Ready ABI Prism, versão 3); 3,2 pmols do iniciador (ora pA-F, ora pc5B-R); $100 \mathrm{ng}$ do amplicom molde; 4,6 $\mu \mathrm{L}$ de tampão (400 mM Tris-HCl, pH 9; $10 \mathrm{mM}$ de $\mathrm{MgCl}_{2}$ ); e água Milli-Q para um volume final de $10 \mu \mathrm{L}$. Para a precipitação, foram adicionados $80 \mu \mathrm{L}$ de isopropanol $75 \%$ às amostras, que foram agitadas ligeiramente e, após 15 min em repouso, à temperatura ambiente, foram centrifugadas a $3.220 \mathrm{~g}$ por $45 \mathrm{~min}$, a $20^{\circ} \mathrm{C}$. O sobrenadante foi descartado e a placa deixada por 5 min em temperatura ambiente, invertida, sobre papel absorvente. Foram adicionados $200 \mu \mathrm{L}$ de etanol 70\% e a microplaca foi submetida à centrifugação a $3.220 \mathrm{~g}$ por $10 \mathrm{~min}$, a $20^{\circ} \mathrm{C}$. Então, o sobrenadante foi novamente dispensado e a placa novamente invertida sobre papel absorvente e submetida a uma breve centrifugação. As amostras foram secas em fluxo laminar, por $30 \mathrm{~min}$. A desnaturação foi realizada com formamida Hi-Di (P/N 4311320, Applied Biosystems, EUA), a $95^{\circ} \mathrm{C}$, por 5 min, seguida pelo sequenciamento no ABI Prism 3700 DNA Analyzer (Applied Biosystems).

A verificação da qualidade das sequências geradas foi realizadapeloprograma Sequencing Analysis 3.4(Applied Biosystems), que gerou arquivos com o eletroforetrograma de cada sequência. Esses eletroforetrogramas foram inicialmente analisados com o auxílio dos programas Phred (Ewing et al., 1998), Phrap e Consed (Gordon et al., 1998), e os arquivos foram analisados pelo programa "practical extraction and reporting language" (Perl linguagem prática para extração e relatórios) desenvolvido no laboratório, e aqueles que tiveram as sequências com menos de 100 nucleotídeos com qualidade inferior a 20 foram descartados, para permitir maior confiabilidade nos resultados. Em seguida, as sequências foram submetidas à consulta de similaridade de nucleotídeos por meio do programa Blastn (“Basic Local Alignment Search Tool”) (Altschul et al., 1997), para comparação com sequências homólogas depositadas no banco de dados público mundial GenBank (National Center for Biotechnology Information - NCBI) (http://www.ncbi.nlm.nih.gov).

As sequências alinhadas e o consenso foram visualizados e analisados no editor de sequências Consed (Gordon et al., 1998). Esse alinhamento foi feito pelo programa Clustalx v.1.81 (Thompson et al., 1997) com base no gene $16 S$ rRNA, com o propósito de agrupar as bactérias nos respectivos gêneros, usando os seguintes parâmetros: "Pairwise Alignment" (Gap Opening 10.00, Gap Extension 0.10), "Multiple Alignment" (Gap Opening 10.00, Gap Extension 0.10). Para matriz de distância das árvores filogenéticas, foi utilizado o algoritmo Jukes-Cantor (Jukes \& Cantor, 1969) e o método "neighbor-joining” de construção de filogramas, que foram processados pelo programa de Análise Genética de Evolução Molecular Mega3 (Kumar et al., 2004) aplicando um "bootstrap" de 1.000 vezes para inferência estatística. Para efeito de comparação com as árvores filogenéticas, obtidas a partir das sequências das estirpes estudadas, foram construídas também árvores filogenéticas, tanto pela direção "forward" quanto pela direção "reverse", com sequências obtidas do GenBank de estirpes que tiveram a região que codifica o gene $16 S$ rRNA sequenciada por completo.

\section{Resultados e Discussão}

A qualidade do sequenciamento dos produtos de PCR purificados, tanto no sentido "forward" como 
no "reverse", foi adequada e produziu sequências de 200 a 600 pb. O resumo dos relatórios obtidos do Blastn encontra-se na Tabela 1. A disponibilidade de numerosas sequências de nucleotídeos derivadas dos genes 16S rRNA, depositadas em bancos de dados públicos, ampliou e facilitou a identificação de bactérias diazotróficas. A qualidade das sequências utilizadas neste trabalho foi amplamente assegurada, ainda que as sequências fossem parciais. Por terem sido feitas algumas repetições, foram utilizados os programas Phrap e Consed, para a avaliação da qualidade por meio da obtenção de seqüências-consenso.

A maior parte das sequências das estirpes padrão e das estirpes recomendadas para inoculação, tanto pelo sentido "forward" quanto pelo "reverse”, apresentaram correspondência com suas respectivas parentais na sequência de bases dessa região cromossômica conservada em relação à identidade de sequências. Entretanto, a Semia 6069 (Bradyrhizobium sp.) apresentou homologia com sequências de Rhizobium sp.; a Semia 6161 (Bradyrhizobium sp.) e Semia 6162 (Bradyrhizobium sp.) apresentaram homologia com Ensifer sp.; a Semia 3012 (Rhizobium leguminosarum bv. viceae) e Semia 396 (R. leguminosarum bv. viceae) apresentaram homologia com Mesorhizobium sp.; a Semia 6168 (Bradyrhizobium sp.) apresentou homologia com $R$. tropici e a Semia 6153 (Bradyrhizobium sp.) apresentou homologia com Sinorhizobium xinjiangensis. Em todos estes casos as homologias foram verificadas em ambos os sentidos das sequências obtidas.

Menna et al. (2006) estudaram 66 estirpes de rizóbios Semia pelo sequenciamento do gene $16 S$ rRNA e pela construção de árvores filogenéticas e detectaram que não há uma relação evidente entre a diversidade do gene 16S rRNA dessas estirpes e a especificidade de suas plantas hospedeiras. Muitas delas, quando tiveram suas sequências comparadas no banco de dados Blastn, apresentaram classificação diversa à sugerida pela Mircen (Microbial Resources Centre Network). Os autores concluíram que o conhecimento genético sobre essas estirpes ainda é bastante deficiente. Vinte e duas das estirpes estudadas por Menna et al. (2006) são coincidentes com as do presente estudo.

As sequências das estirpes Semia 103, Semia 396, Semia 6157, Semia 6161 e Semia 6192, depositadas no banco de dados mundial (NCBI) por Menna e colaboradores, permaneceram entre as cinco com maior identidade de sequências com aquelas do presente estudo quando analisadas no Blastn. Além destas, as estirpes Semia 135, Semia 587, Semia 656, Semia 695, Semia 816, Semia 2051, Semia 3007, Semia 5019, Semia 5080, Semia 6145, Semia 6156, Semia 6158, Semia 6168, Semia 6175 e Semia 6319 apresentaram identidade de sequências com as espécies das estirpes semelhantes, que foram sequenciadas por Menna. Atualmente, Semia 396, Semia 6161 e Semia 6168 têm como classificação, respectivamente, $R$. leguminosarum bv. viciae, Bradyrhizobium sp. e Bradyrhizobium sp. Entretanto, de acordo com os resultados obtidos por Menna et al. (2006) e os do presente estudo, essas estirpes deveriam ser classificadas como Rhizobium sp., Ensifer sp. e Mesorhizobium ciceri, respectivamente. Também, as estirpes Semia 587, Semia 5019, Semia 6157, Semia 6158 e Semia 6175 ficaram agrupadas com $B$. elkanii, enquanto a estirpe Semia 5080 ficou agrupada com B. japonicum nas árvores construídas neste trabalho, o que corrobora os resultados de sequenciamento do gene $16 S r R N A$ obtidos por Menna et al. (2006). Observa-se que algumas dessas 22 estirpes coincidentes não apresentaram identidades de sequências. É o caso da estirpe Semia 384, cuja classificação atual é de $R$. leguminosarum bv. trifolii, que manteve esta classificação no presente trabalho, embora Menna et al. (2006) tenham sugerido classificála como $R$. etli, e o caso da estirpe Semia 6069 que apresentou identidade de sequência com Rhizobium sp. no presente estudo, cuja classificação atual é Bradyrhizobium sp., e proposta como B. elkanii por Menna et al. (2006).

As sequências "forward" e "reverse", obtidas do Genbank (NCBI), produziram árvores idênticas, conforme o esperado, e dividiram as estirpes em alguns grupos (Figura 1 ). As estirpes de $B$. japonicum e B. elkani formaram um grupo monofilético. As estirpes Mesorhizobium mediterraneum, M. tianshanense, M. amorphae, M. huaikuii, M. plurifarium, M. loti e $M$. ciceri formaram outro grupo monofilético. As estirpes de Ensifer terangae, E. meliloti e E. fredii formaram um grupo mais proximamente relacionado ao grupo monofilético das estirpes de Rhizobium ( $R$. leguminosarum, $R$. etli, $R$. tropici, $R$. mongolense, $R$. gallicum, $R$. yanglingense, $R$. galegae, $R$. huautlense, $R$. undicola e $R$. giardinii). Na árvore filogenética construída pelo sentido "forward" com as estirpes estudadas, foi observada uma clara divisão de um 


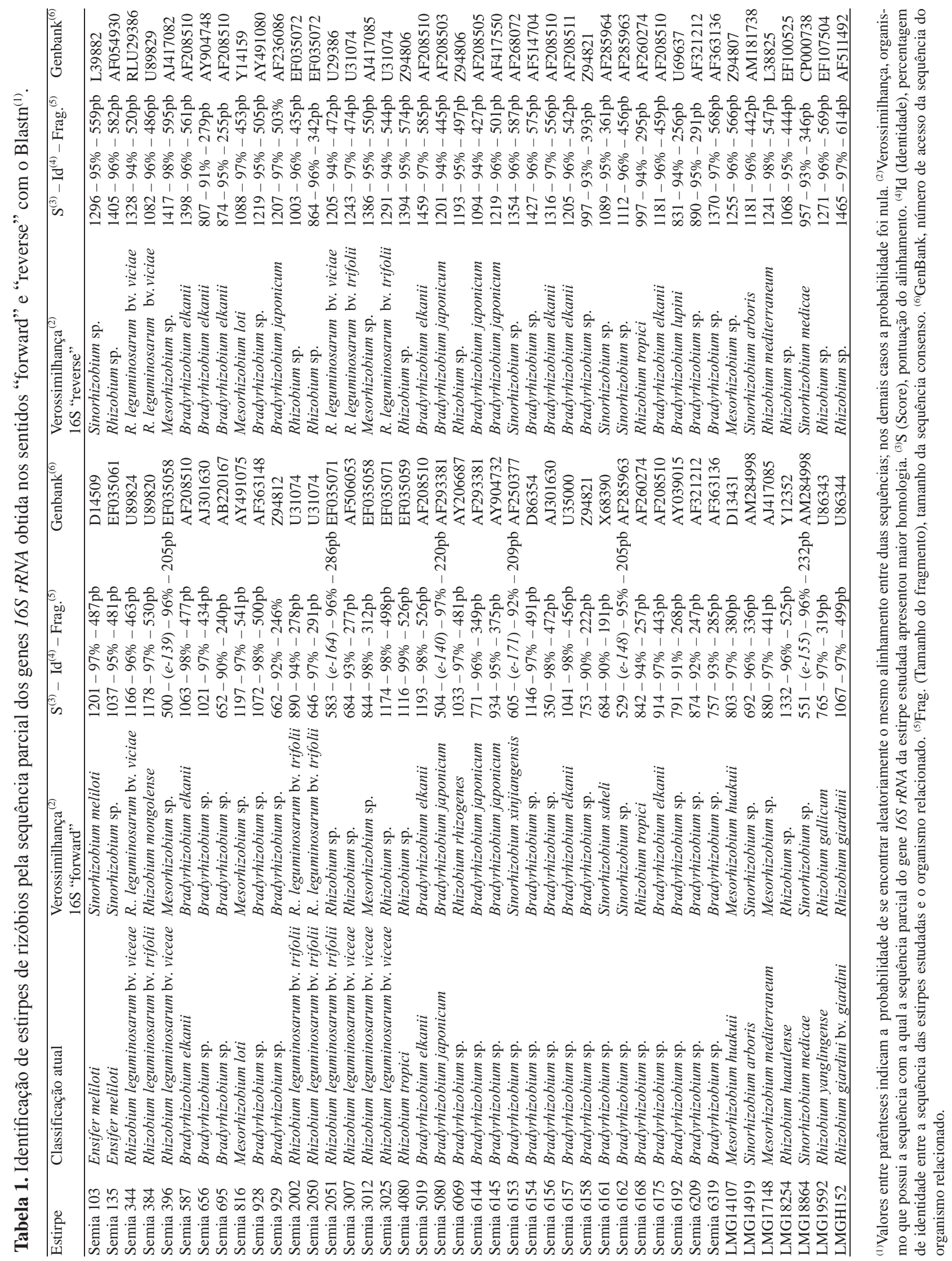


grupo de Bradyrhizobium em dois subgrupos: um subgrupo composto por Bradyrhizobium sp. (estirpes Semia 587, Semia 6157, Semia 6175, Semia 656, Semia 6156, Semia 928, Semia 6154 e Semia 5019) agrupado com a espécie B. elkanii; e outro subgrupo que contém Bradyrhizobium sp. (estirpes Semia 929, Semia 6145, Semia 5080 e Semia 6144) agrupado com B. japonicum (Figura 2). $\mathrm{Na}$ árvore construída pelo sentido "reverse", foi observado o mesmo tipo de agrupamento, porém o grupo monofilético das estirpes semelhantes a B. elkanii incluiu as mesmas da árvore "forward", com exceção das Semia 928 e Semia 6154, que, nesta árvore, entraram no grupo de B. japonicum, e incluiu também as Semia 695 e Semia 6158, que na árvore "forward" formavam um grupo à parte (Figura 3 ). O grupo de estirpes semelhantes a $B$. japonicum da árvore obtida pela direção "reverse" compreendeu Semia 929, Semia 6145 e Semia 5080 (como na árvore “forward”), além das estirpes Semia 6319, Semia 6192 e Semia 6209 (que estavam em um grupo à parte na árvore "forward") e Semia 928 e Semia 6154 (que estavam próximas a estirpes de $B$. elkanii na outra árvore). A dificuldade em separar espécies de Bradyrhizobium deve-se à baixa variabilidade genética entre elas, o que impossibilita, muitas vezes, a diferenciação entre B. japonicum e B. elkanii (Chueire et al., 2000).

$\mathrm{Na}$ árvore construída pelo sentido "forward", as estirpes de Rhizobium, Ensifer e Mesorhizobium permaneceram intercaladas, formando grupos polifiléticos, como ocorreu na árvore construída pelo sentido "reverse" do 16S rRNA. A árvore obtida pelo sentido "reverse" formou um grupo composto pelas estirpes de Mesorhizobium LMG 17148, LMG 14107, Semia 3012, Semia 816 e Semia 396. Embora a estirpe Semia 396 seja classificada atualmente como $R$. leguminosarum bv. viceae, segundo este trabalho e o de Menna et al. (2006) essa estirpe corresponde a Mesorhizobium sp. As estirpes de Ensifer LMG 14919, LMG 18864, Semia 6153, Semia 103, Semia 135, Semia 6161 e Semia 6162 permaneceram próximas entre si e mais diretamente relacionadas ao conjunto de estirpes de Rhizobium sp., composto por H152, Semia 6168, Semia 2002, Semia 4080, Semia 6069, Semia 2051, Semia 344, Semia 3025, Semia 384, Semia 3007, Semia 2050 e LMG 19592. É importante observar que as estirpes Semia 6162 e Semia 6168, ambas classificadas atualmente como Bradyrhizobium sp., pelos resultados deste trabalho e os de Menna et al. (2006) deveriam ser reclassificadas como Ensifer sp. e Rhizobium sp., respectivamente. As estirpes Semia 384 e Semia 6069, classificadas como $R$. leguminosarum bv. trifolii e Bradyrhizobium sp., respectivamente, de acordo com a árvore obtida pelo sentido "forward" e pelo sentido "reverse" permaneceram agrupadas com estirpes de Rhizobium, diferentemente do sugerido por Menna et al. (2006), o que confirmou os resultados da análise de similaridade (Blastn).

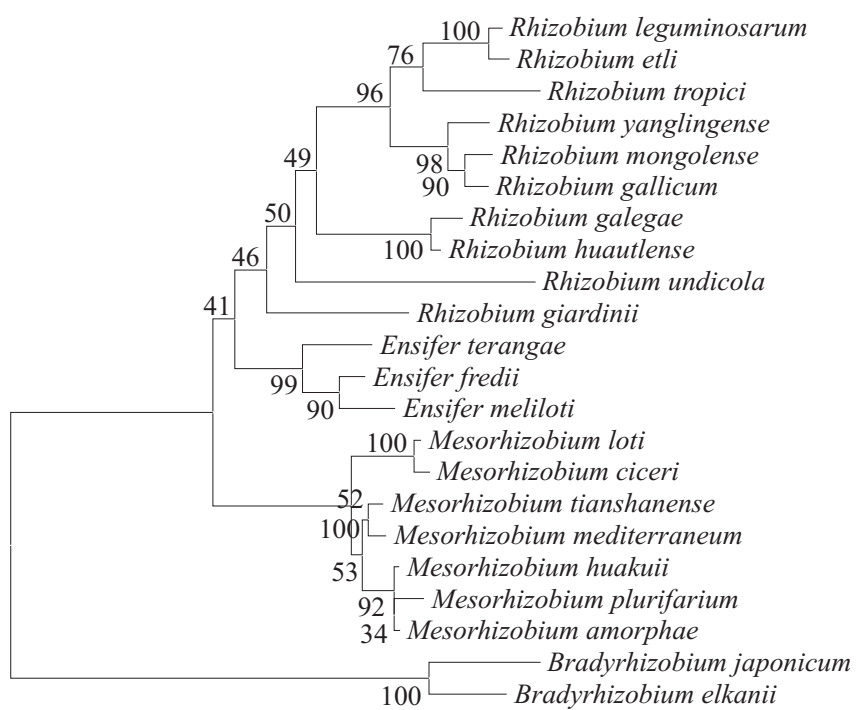

0,01

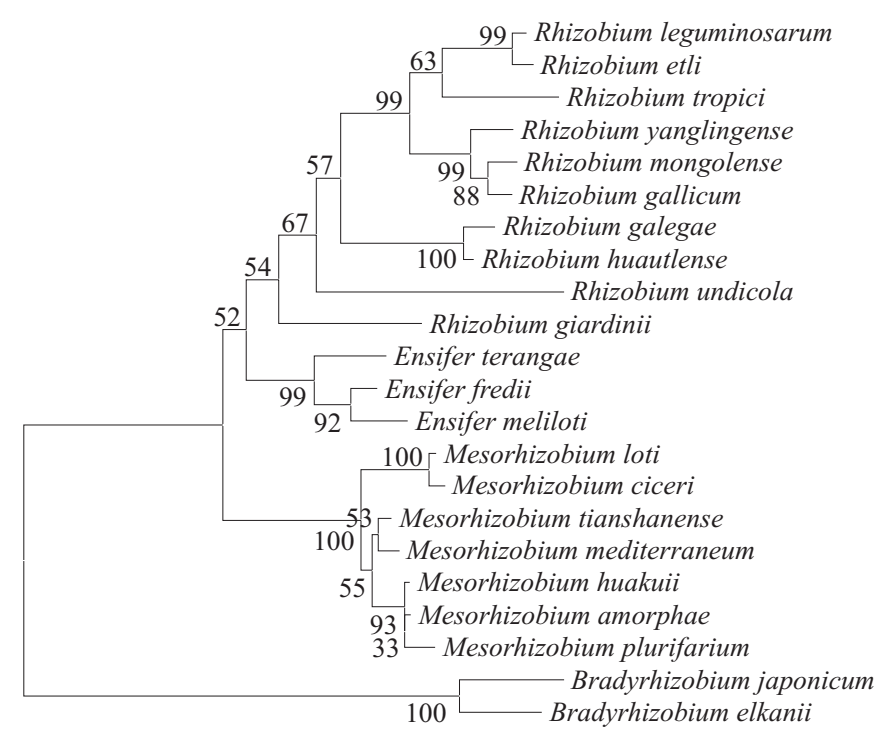

0,01

Figura 1. Árvores filogenéticas baseadas nas sequências parciais do gene $16 S$ rRNA obtidas pelo sentido "forward" (à esquerda) e "reverse" (à direita), no Genbank. Valores de "bootstrap" estão indicados na árvore. 
Informações sobre a estrutura das populações de rizóbios, bem como sobre a evolução dos microssimbiontes, são importantes, porque podem contribuir não só para delinear estratégias que visem maximizar o processo de fixação biológica do nitrogênio, como também para obter informações sobre a evolução da simbiose (Grange et al., 2007). A classificação taxonômica das estirpes Semia recomendadas para inoculação de leguminosas previamente disponíveis na Fepagro, elaborada com

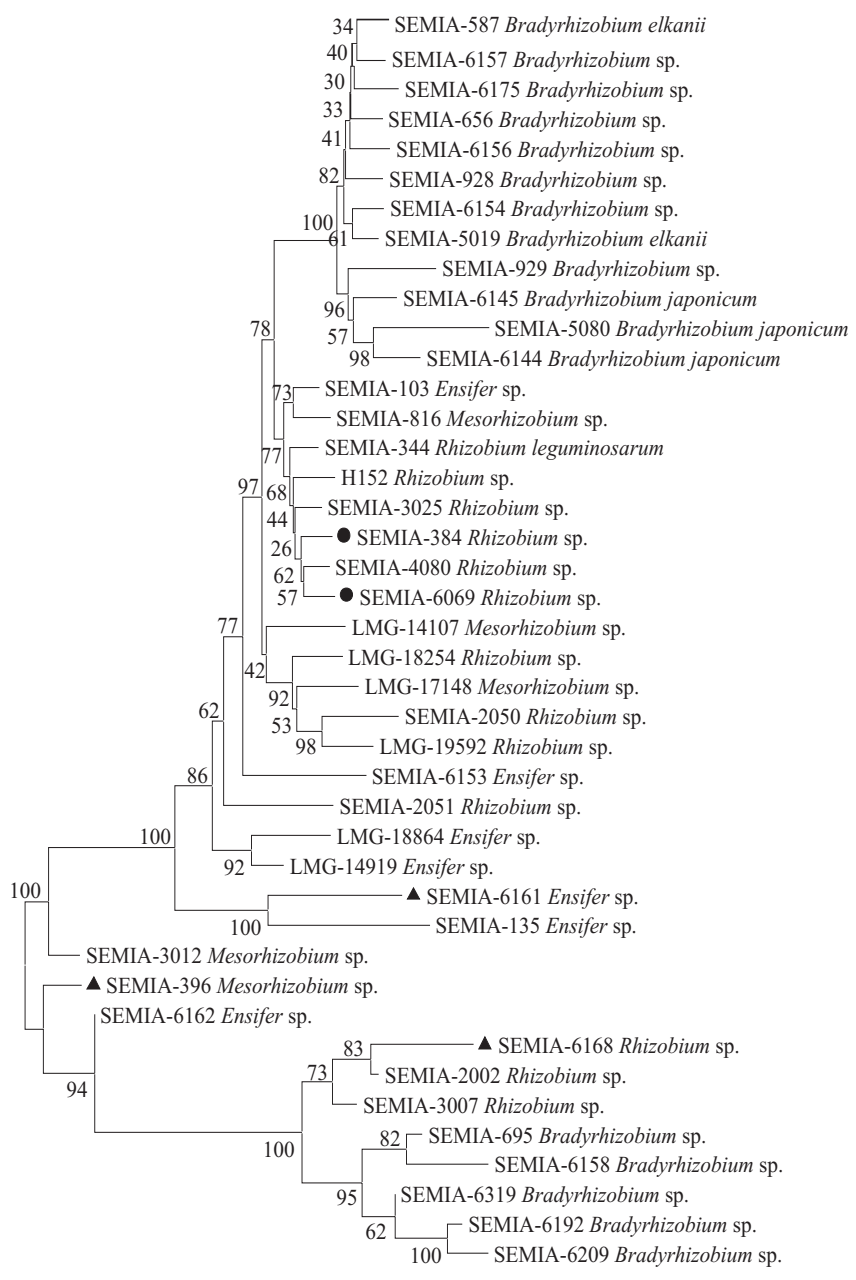

0,1

Figura 2. Árvore filogenética baseada nas sequências parciais do gene $16 S$ rRNA das estirpes estudadas, obtidas pelo sentido "forward". $\boldsymbol{\Lambda}$, estirpes que neste trabalho e no de Menna et al. (2006) obtiveram classificação diferente da atualmente conhecida; •, estirpes que neste trabalho obtiveram classificação diferente da sugerida por Menna et al. (2006). Valores de "bootstrap" estão indicados na árvore. base em propriedades morfológicas e especificidade hospedeira, foi confirmada para a maior parte das estirpes. Entretanto, algumas foram identificadas como pertencentes a outros gêneros. As estirpes Semia 6162, Semia 6161, Semia 6153 e Semia 6144, que são classificadas como Bradyrhizobium sp. neste trabalho, foram caracterizadas como estirpes do gênero Ensifer. As estirpes Semia 3012 e Semia 396, classificadas como

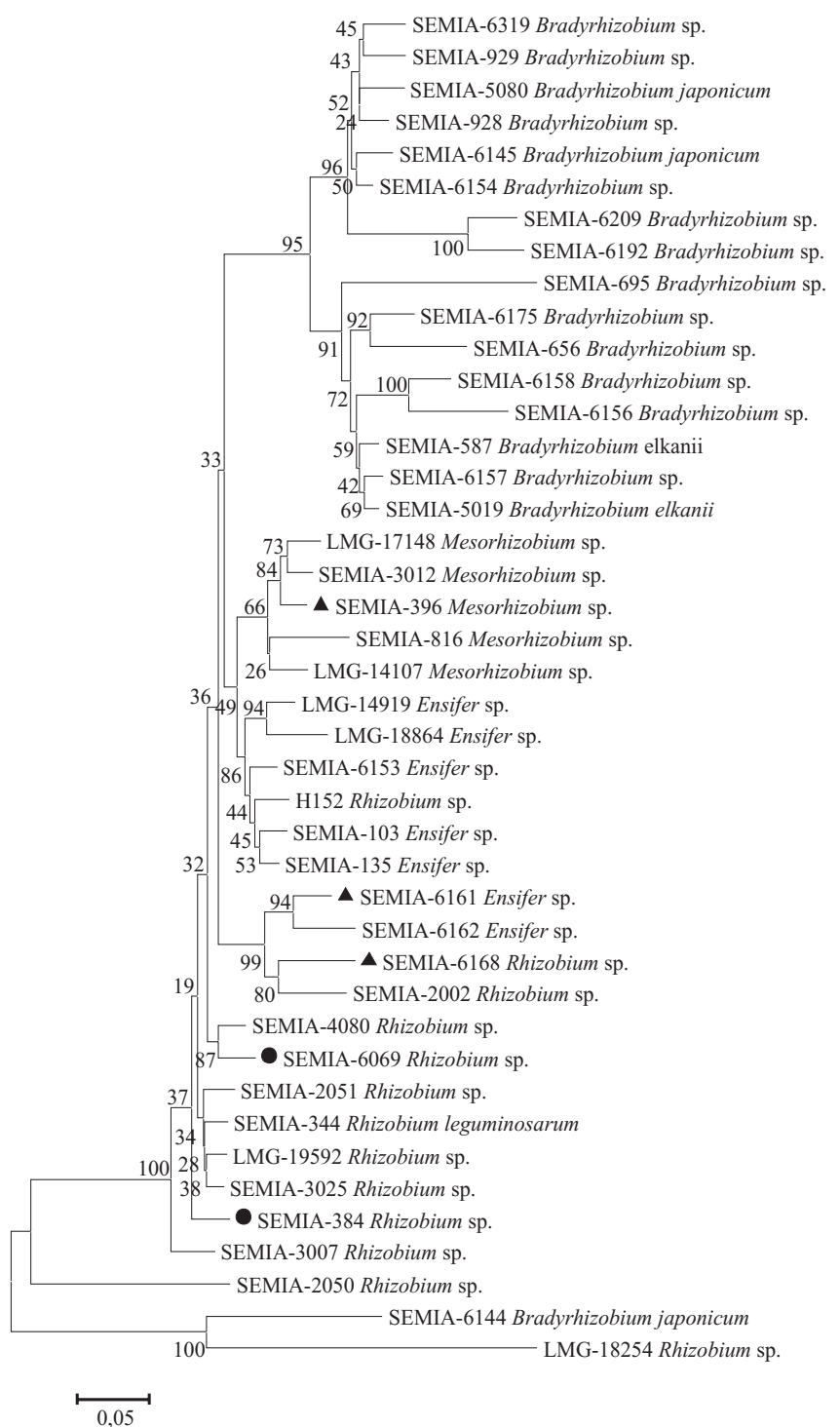

Figura 3. Árvore filogenética baseada nas sequências parciais do gene $16 S$ rRNA das estirpes estudadas, obtidas pelo sentido "reverse". $\boldsymbol{\Lambda}$, estirpes que neste trabalho e no de Menna et al. (2006) obtiveram classificação diferente da atualmente conhecida; •, estirpes que neste trabalho obtiveram classificação diferente da sugerida por Menna et al. (2006). Valores de "bootstrap" estão indicados na árvore. 
$R$. leguminosarum bv. viciae, foram caracterizadas como Mesorhizobium sp. neste trabalho; as estirpes de Bradyrhizobium sp. Semia 6168 e Semia 6069 foram identificadas como pertencentes ao gênero Rhizobium. Ao se considerarem as árvores filogenéticas, observase que a grande maioria dos grupos monofiléticos formados obedecem às classificações realizadas pela consulta ao Blastn.

\section{Conclusão}

O sequenciamento parcial da região do gene 16S rRNA é suficiente para a identificação de estirpes de rizóbios com base na similaridade desse gene no Blastn.

\section{Referências}

ALTSCHUL, S.F.; MADDEN, T.L.; SCHÄFFER, A.A.; ZHANG, J.; ZHANG, Z.; MILLER, W.; LIPMAN, D.J. Gapped Blast and PSI-Blast: a new generation of protein database search programs. Nucleic Acids Research, v.25, p.3389-3402, 1997.

BERINGER, J.E.R. Factor transfer in Rhizobium leguminosarum. Journal of General Microbiology, v.84, p.188-198, 1974.

BROSIUS, J.; PALMER, M.L.; KENNEDY, P.J.; NOLLER, H.F. Complete nucleotide sequence of a 16S ribosomal RNA gene from Escherichia coli. Proceedings of The National Academy of Sciences of The United States of America, v.75, p.4801-4805, 1978.

CHUEIRE, L.M. de O.; NISHI, C.Y.M.; LOUREIRO, M. de F.; HUNGRIA, M. Identificação das estirpes Bradyrhizobium e Rhizobium utilizadas em inoculantes comerciais para as culturas da soja e do feijoeiro pela técnica de PCR com “primers” aleatórios ou específicos. Agricultura Tropical, v.4, p.80-95, 2000.

EWING, B.; HILLER, L.; WENDL, M.C.; GREEN, P. Base-calling of automated sequencer traces using Phred. I. Accuracy assessment. Genome Research, v.8, p.175-85, 1998.

FUNDAÇÃO ESTADUAL DE PESQUISA AGROPECUÁRIA. Culture collection catalogue. $8^{\text {th }}$ ed. Porto Alegre: Fepagro, 1999.
GARRITY, G.M.; HOLT, J.G. The road map to the manual. In: BOONE, D.R.; CATENHOLZ, R.W. (Ed.). Bergey's manual of systematic bacteriology. New York: Springer-Verlag, 2001. v.1. p.119-166.

GARRITY, G.M.; LILBURN, T.G.; COLE, J.R.; HARRISON, S.H.; ENZEBY, J.; TINDALL, B.J. Taxonomic outline of bacteria and archaea: TOBA release 7.7. Michigan: Michigan State University, 2007. Disponível em: <http://www.taxonomicoutline.org>. Acesso em: 1ํㅡar. 2008.

GORDON, D.; ABAJIAN, C.; GREEN, P. Consed: a graphical tool for sequence finishing. Genome Research, v.8, p.195-202, 1998.

GRANGE, L.; HUNGRIA, M.; GRAHAN, P.H.; MARTINEZROMERO, E. New insights into the origins and evolution of rhizobia that nodulate common bean (Phaseolus vulgaris) in Brazil. Soil Biology \& Biochemistry, v.39, p.867-876, 2007.

JUKES, T.H.; CANTOR, C.R. Evolution of protein molecules. In: MUNRO, H.N. (Ed.). Mammalian protein metabolism. New York: Academic Press, 1969. p.21-132.

KUMAR, S.; TAMURA, K.; NEI, M. MEGA3: integrated software for molecular evolutionary genetics analysis and sequence alignment. Briefings Bioinformatics, v.5, p.150-163, 2004.

MENNA, P.; HUNGRIA, M.; BARCELLOS, F.G.; BANGEL, E.V.; HESS, P.N.; MARTINEZ-ROMERO, E. Molecular phylogeny based on the 16S rRNA gene of elite rhizobial strains used in Brazilian commercial inoculants. Systematic Applied Microbiology, v.29, p.315-332, 2006.

OLSEN, G.J.; WOESE, C.R. Ribosomal RNA: a key to phylogeny. Faseb Journal, v.7, p.113-123, 1993.

SAMBROOK, J.; FRITSCH, E.F.; MANIATIS, T. Molecular cloning: a laboratory manual. $2^{\text {nd }}$ ed. New York: Cold Spring Harbor Laboratory Press, 1989.

THOMPSON, J.D.; GIBSON, T.J.; PLEWNIAK, F.; JEANMOUGIN, F.; HIGGINS, D.G. The CLUSTAL_X windows interface: flexible strategies for multiple sequence alignment aided by quality analysis tools. Nucleic Acids Research, v.25, p.4876-4882, 1997.

VINCENT, J.M. A manual for the practical study of root-nodule bacteria. Oxford: Blackwell Scientific, 1970. 164p.

WILSON, K.H.; BLITCHINGTON, R.B.; GREENE, R.C. Amplification of bacterial 16S ribosomal DNA with polymerase chain reaction. Journal of Clinical Microbiology, v.28, p.1942-1946, 1990.

Recebido em 27 de outubro de 2008 e aprovado em 31 de março de 2009 